\title{
VARIAÇÃO DA TEMPERATURA DE SUPERFÍCIE ATRAVÉS DE TÉCNICAS DE SENSORIAMENTO REMOTO: ANÁLISE DE DOIS EPISÓDIOS PARA O CONCELHO DE COIMBRA, PORTUGAL/2018
}

\author{
NASCIMENTO, Fabrício Holanda do - fabricio.climatologia2015@gmail.com \\ Universidade Federal do Espírito Santo / UFES
}

JARDIM, Carlos Henrique - cjardim@yahoo.com

Universidade Federal de Minas Gerais / UFMG

RANGEL, Silênia de Azevedo Silveira - sileniarangel@gmail.com

Universidade Federal do Espírito Santo / UFES

Submetido em: 19/08/2020

Aceito para publicação em: 09/01/2021

Publicado em: 06/04/2021

DOI: http://dx.doi.org/10.5380/abclima.v28i0.75954

\begin{abstract}
RESUMO: Esta pesquisa tem o objetivo de identificar e analisar a variação das temperaturas de superfície do Concelho de Coimbra, Portugal, por meio de técnicas de Sensoriamento Remoto, em dois períodos, no verão e no inverno de 2018 , bem como relacionar as classes de temperatura com o uso e cobertura do solo e a morfologia do terreno. Para tanto, foram feitos levantamentos bibliográficos entre livros, teses, dissertações e artigos científicos que discorrem sobre os principais conceitos aqui tratados (Clima, Climatologia Geográfica, Sensoriamento Remoto, Sistemas de Informações Geográficas etc.), aquisição de bases cartográficas (vetoriais e raster) para a elaboração dos mapas e aplicação de recursos técnicos de geoprocessamento de imagens de satélite. Os resultados mostraram diferenças significativas na variação das temperaturas, mais elevadas nas áreas urbanas comparativamente às áreas de agricultura/pastagens $\left(6^{\circ} \mathrm{C}\right)$ e providas de cobertura florestal $\left(7,5^{\circ} \mathrm{C}\right)$, tanto no verão quanto no inverno, associadas às propriedades diferenciadas quanto à produção, propagação e conservação de calor no ambiente.
\end{abstract}

PALAVRAS-CHAVE: Sensoriamento Remoto; Infravermelho Termal; Clima Urbano; Climatologia Geográfica; Planejamento Territorial.

VARIATION OF SURFACE TEMPERATURE THROUGH REMOTE SENSING TECHNIQUES: ANALYSIS OF TWO EPISODES FOR THE COIMBRA COUNTY, PORTUGAL / 2018

ABSTRACT: This research aims to identify and analyze the variation of surface temperatures in the Municipality of Coimbra, Portugal, using Remote Sensing techniques, in two periods, in the summer and winter of 2018, as well as to relate the temperature classes with the land use and cover and the morphology of the terrain. To this end, bibliographical surveys were made between books, theses, dissertations and scientific articles that discuss the main concepts treated here (Climate, Geographic Climatology, Remote Sensing, Geographic Information Systems, etc.), acquisition of cartographic bases (vector and raster) for the elaboration of maps and application of technical resources for geoprocessing satellite images. The results showed significant differences in temperature variation, higher in urban areas compared to agricultural / pasture areas (6 ${ }^{\circ} \mathrm{C}$ ) and provided with forest cover $\left(7.5^{\circ} \mathrm{C}\right)$, both in summer and in winter, associated with different properties in terms of the production, propagation and conservation of heat in the environment.

KEYWORDS: Remote Sensing; Thermal Infrared; Urban Climate; Geographic Climatology; Territorial Planning. 
VARIACIÓN DE LA TEMPERATURA SUPERFICIAL MEDIANTE TÉCNICAS DE SENSIÓN REMOTA: ANÁLISIS DE DOS EPISODIOS PARA EL CONDADO DE COIMBRA, PORTUGAL / 2018

RESUMEN: Esta investigación tiene como objetivo identificar y analizar la variación de temperaturas superficiales en el municipio de Coimbra, Portugal, utilizando Teledetección, en dos periodos, en el verano e invierno de 2018, así como relacionar las clases de temperatura con el uso y cobertura del suelo y la morfología del terreno. Para ello, se realizaron levantamientos bibliográficos entre libros, tesis, disertaciones y artículos científicos que discuten los principales conceptos aquí tratados (Clima, Climatología Geográfica, Teledetección, Sistemas de Información Geográfica, etc.), adquisición de bases cartográficas (vectoriales y raster) para la elaboración de mapas y aplicación de recursos técnicos para el geoprocesamiento de imágenes satelitales. Los resultados mostraron diferencias significativas en la variación de temperatura, mayor en las áreas urbanas en comparación con las áreas agrícolas / de pasto $\left(6^{\circ} \mathrm{C}\right)$ y dotado de cobertura forestal $\left(7,5^{\circ} \mathrm{C}\right)$, tanto en verano como en invierno, asociado a diferentes propiedades en cuanto a producción, propagación y conservación del calor en el medio.

PALABRAS CLAVE: Detección Remota; Infrarrojos Térmicos; Clima Urbano; Climatología Geográfica; Planificación Territorial.

\section{INTRODUÇÃO}

A preocupação com os fenômenos de ordem climática não é recente. Desde há muito tempo o Homem se preocupa em conhecer os fenômenos que ocorrem na atmosfera, fato que fica claro em obras clássicas como a de Aristóteles e Hipócrates e são exemplos disso, em Meteorológica e Ares, Águas e Lugares, respectivamente.

Neste trabalho o clima é compreendido como dinâmico, considerando o conceito de Sorre $(1951)$ e Monteiro $(1971 ; 1976)$ que, além do dinamismo do clima, confere ênfase também ao ritmo (características e frequência em que um fenômeno ocorre) como algo essencial ao clima. Assim, o clima é considerado como "[...] à série dos estados atmosféricos sobre um determinado lugar em sua sucessão habitual" (SORRE, 1951, p.90).

O Clima influencia o Homem através de seus elementos ou atributos e o Homem influencia o clima, sobretudo na escala local (ou inferior), por meio de suas diversas atividades, em especial por meio das modificações do ambiente natural em ambiente "artificializado" das cidades (AYOADE, 2013; RIBEIRO, 2009; MENDONÇA; DANNI-OLIVEIRA, 2007; LANDSBERG, 2006).

É nas cidades que ocorrem as maiores intervenções do Homem sobre a Natureza, em especial nas modificações da composição da atmosfera (LOMBARDO, 1985; LANDSBERG, 2006). Coelho (2003) afirma que as alterações intensas ao ambiente, devido às ocupações humanas, ocorrem em consequência da falta de planejamento adequado que vise atenuar os efeitos nocivos ao ambiente. Mills (2014) afirma que as áreas urbanas têm efeito profundo sobre a atmosfera, resultante das mudanças na natureza da cobertura das superfícies (originando formas urbanas), da emissão de calor, do vapor d'água e dos materiais que atendem às atividades humanas (funções urbanas).

Destarte, a influência exercida pelas atividades humanas, em especial pela urbanização, corrobora para a formação de um clima peculiar, ou seja, um clima urbano, conforme aponta Monteiro (1976, p.95), "um sistema que abrange um clima de um dado espaço terrestre e sua urbanização". Nesta mesma perspectiva, Ganho (1999) afirma que independente da dimensão, 
sejam elas de grande porte ou modestas, as áreas urbanizadas "[...] interferem significativamente nas características climáticas locais, criando, nomeadamente, o seu próprio campo de temperaturas" (p.99).

Ao longo do tempo, diversos estudos surgiram na tentativa de compreender a relação da atmosfera com a superfície subjacente. Landsberg (2006) lista uma série de trabalhos nessa linha de pesquisa, a exemplo de Luke Howard (1833), em Londres, Kratzer (1937), Brooks (1952), e mais recentemente os trabalhos de Stewart; Oke (1987), Jensen (2009) e Chander et al. (2009).

Nos Estados Unidos da América (EUA), Quattrochi e Ridd (1994) e Lo et al. (1997), avaliaram a temperatura de superfície nas cidade de Salt Lake City, Utah, e Huntsville, no Alabama, por meio do uso de SR em períodos diurnos e noturnos a partir de imagens de alta resolução espacial. Os autores observaram que durante o dia as faixas de temperaturas mais elevadas estavam associadas às áreas comerciais e industriais, conquanto que as faixas de temperaturas mais baixas estavam associadas aos corpos hídricos, a vegetação e as terras agrícolas. Todavia, durante a noite, as áreas comerciais e industriais esfriavamse mais rapidamente do que as áreas com vegetação e os corpos hídricos, evidenciando grande contraste térmico entre essas áreas e as de uso comercial e industrial, favorecendo a formação de ilhas de calor.

Rocha; Cordeiro; Gonçalves (2014), fizeram uso do SR para identificar "ilhas de calor" e "lago de ar frio" no Município de Oliveira do Hospital, Coimbra, Portugal. Além dos dados de SR, os autores também fizeram campanhas de campo, afim de verificar as condições de temperatura, por meio de termógrafos, no Município, haja vista a pouca disponibilidade de dados meteorológicos para estudos a nível topoclimático.

Diante dos resultados obtidos, os pesquisadores constataram que as altas temperaturas estavam concentradas nas vertentes com faces voltadas para a porção sul do Município, pois recebem maior quantidade de luz solar, bem como nas áreas mais urbanizadas. Além disso, os autores concluíram que em grande parte da área de estudo havia o fenômeno da "ilha de calor" e ausência de "lago de ar frio" (ROCHA; CORDEIRO; GONÇALVES, 2014).

A região do infravermelho termal compreende uma faixa do Espectro Eletromagnético na qual a radiância captada por um sensor remoto é emitido pelo objeto-alvo da superfície (JESUS, 2016). Nesse sentido, Jensen (2009) afirma que os sensores do infravermelho termal são muito importantes, pois "[...] permitem aos humanos conhecerem um mundo de informação anteriormente invisível, ao monitorarem as características térmicas da paisagem" (p.251).

Assim, o Sensoriamento Remoto (SR) possibilita estudos multitemporais acerca de diversos fenômenos da natureza, em especial das variações das temperaturas dos materiais constituintes da paisagem, contribuindo com 0 conhecimento acerca das transformações, no tempo e no espaço, do uso e cobertura da terra e a influência que essas transformações exercem no comportamento térmico da superfície, em especial das cidades (JENSEN, 2009).

O Sensoriamento Remoto (SR) pode ser considerado como a arte e ciência de se obter informações de um dado objeto sem entrar em contato físico com o mesmo e possibilita medir e monitorar importantes características dos 
meios físico e social da Terra. As informações capturadas dos objetos constituintes do espaço geográfico provém da energia do Sol refletida e/ou absorvida pela superfície, incluindo a temperatura emitida pelos materiais por meio dos sensores do infravermelho termal (FITZ, 2008; JENSEN, 2009).

Em face ao exposto, esta pesquisa tem o objetivo principal de identificar e analisar as variações das temperaturas de superfície por meio de técnicas de Sensoriamento Remoto no Concelho de Coimbra, Portugal, em dois períodos, verão e inverno, no ano de 2018 e relacionar as faixas de temperatura com o uso e cobertura do solo e a morfologia do terreno, visando a produção de subsídios para os planejamento e ordenamento territoriais.

\section{MATERIAIS E MÉTODOS}

\subsection{LOCALIZAÇÃO DA ÁREA DE ESTUDO}

A área de estudo refere-se ao Concelho de Coimbra (Figura 1) que, junto aos municípios de Arganil, Cantanhede, Condeixa-a-Nova, Figueira da Foz, Góis, Lousã, Mealhada, Mira, Miranda do Corvo, Montemor-o-Velho, Mortágua, Oliveira do Hospital, Pampilhosa da Serra, Penacova, Penela, Soure, Tábua e Vila Nova de Poiares, compõem a Região de Coimbra, localizada na porção central de Portugal que possui uma área de $4.335,6 \mathrm{~km}^{2}$ e população de 435.482 habitantes. Já o Município de Coimbra possui área geográfica de 133.940 habitantes, distribuídos em uma área de $319,4 \mathrm{~km}^{2}$, segundo dados estimados para o ano de 2018 (PORDATA, 2020).

Do ponto de vista climático, Coimbra apresenta um clima quente e temperado. Segundo a classificação de Köppen, o clima é definido pela classe Csa, com verão quente de temperatura média mínima de $16^{\circ} \mathrm{C}$ e média máxima de $22^{\circ} \mathrm{C}$, e pluviosidade média anual de 922mm (CLIMATE-DATA, 2020). Ademais, o campo térmico oscila significativamente, com amplitudes térmicas elevadas, pois no inverno a temperatura do ar varia entre 5 e $15^{\circ} \mathrm{C}$, podendo chegar, em alguns casos a $0^{\circ} \mathrm{C}$, sendo que no verão podem ser observados valores de até $40^{\circ} \mathrm{C}$ (PELLEGRINA; CUNHA, 2019).

Segundo Ferreira (2005), em termos mesoclimático, o clima de Coimbra é classificado de acordo com as regiões climáticas de Portugal Continental, e sofre influência da proximidade com o Oceano Atlântico, e se modifica na medida em que se aproxima do Maciço Marginal de Coimbra a leste e do Rio Mondego. 


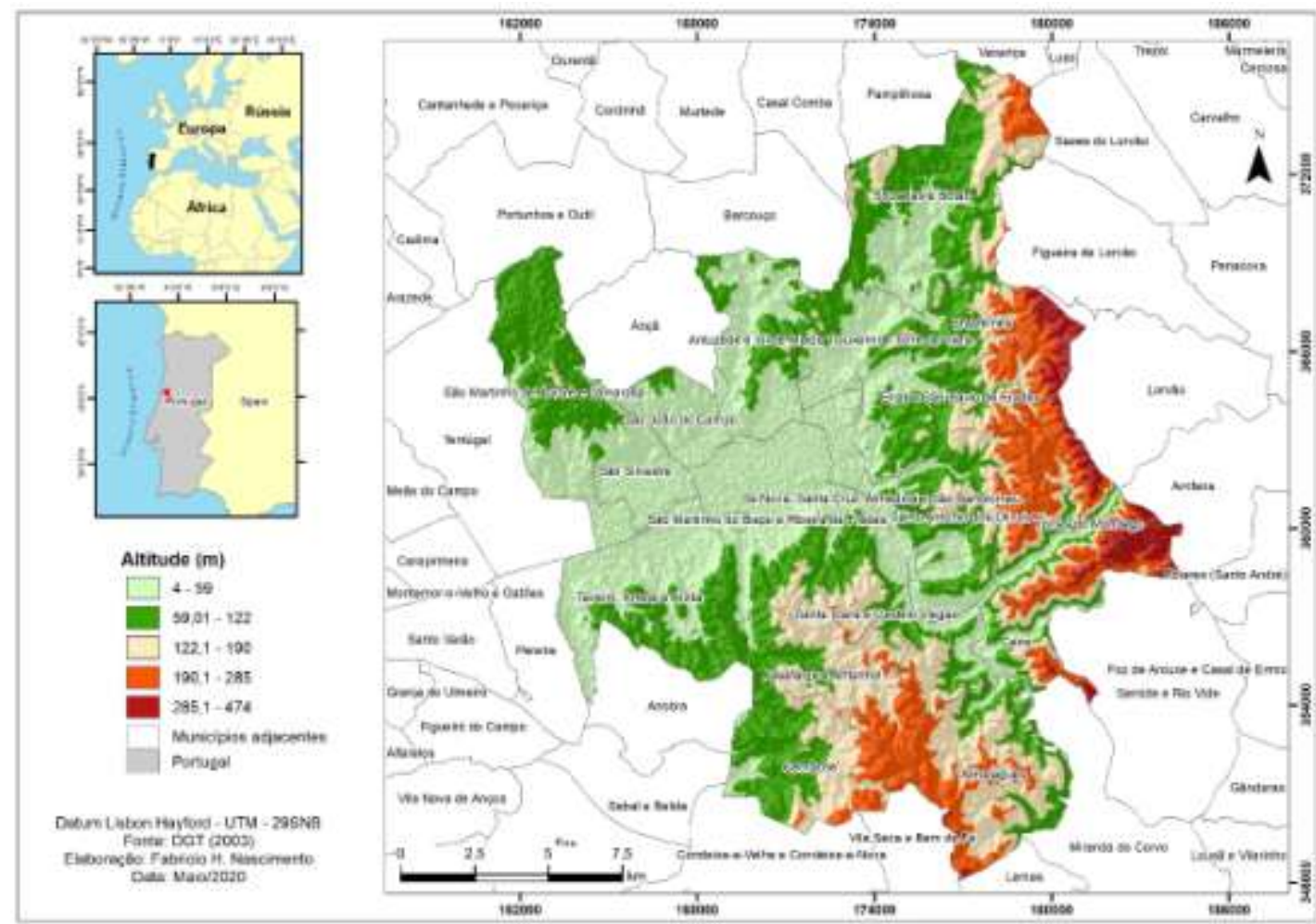

Figura 1 - Localização da área de estudo e altitudes: Coimbra, Portugal. Fonte: DGT/2003. Elaborado pelos autores/2020.

O Modelo Digital de Elevação - MDE (Figura1) e o uso e cobertura do solo do Concelho de Coimbra (Figura 2), são dois atributos importantes, e que deram subsídio às interpretações dos mapas de temperatura de superfície, haja vista que são dois fatores que influenciam a temperatura de um dado lugar (MENDONÇA; DANNI-OLIVEIRA, 2007; AYOADE, 2013). Através da análise da Figura 1, Coimbra possui altitudes que variam de 7 a 316 metros, sendo que as porções Nordeste, Leste, Sudeste e Sul do Município, possuem valores de altitudes mais elevados, variando de 162 a 316 metros, conquanto que as porções Norte, Noroeste e Oeste são caracterizadas por altitudes mais baixas.

O relevo é um importante fator climático, pois sua posição pode favorecer ou dificultar os fluxos de calor que adentram determinada região. Mendonça; Danni-Oliveira (2007), afirmam que o relevo apresenta, pelo menos, três atributos importantes na definição dos climas: "[...] posição, orientação de suas vertentes e a declividade" (p.47).

No que se refere ao uso e cobertura do solo, as Figura 2 e Tabela 1, apresentam a distribuição das classes de uso e a estatística de uso. Assim, é possível perceber que o Concelho de Coimbra possui a maior parte do seu território coberto por florestas $(47,54 \%)$, seguido de agricultura e áreas urbanizadas, com $29,28 \%$ e $18,91 \%$, respectivamente. Nesse contexto, as porções Central, Nordeste e uma pequena faixa da porção Oeste, são majoritariamente caracterizadas por área urbana, nas porções Sul, Leste e uma pequena faixa da porção Norte, são caracterizadas por áreas florestais. 


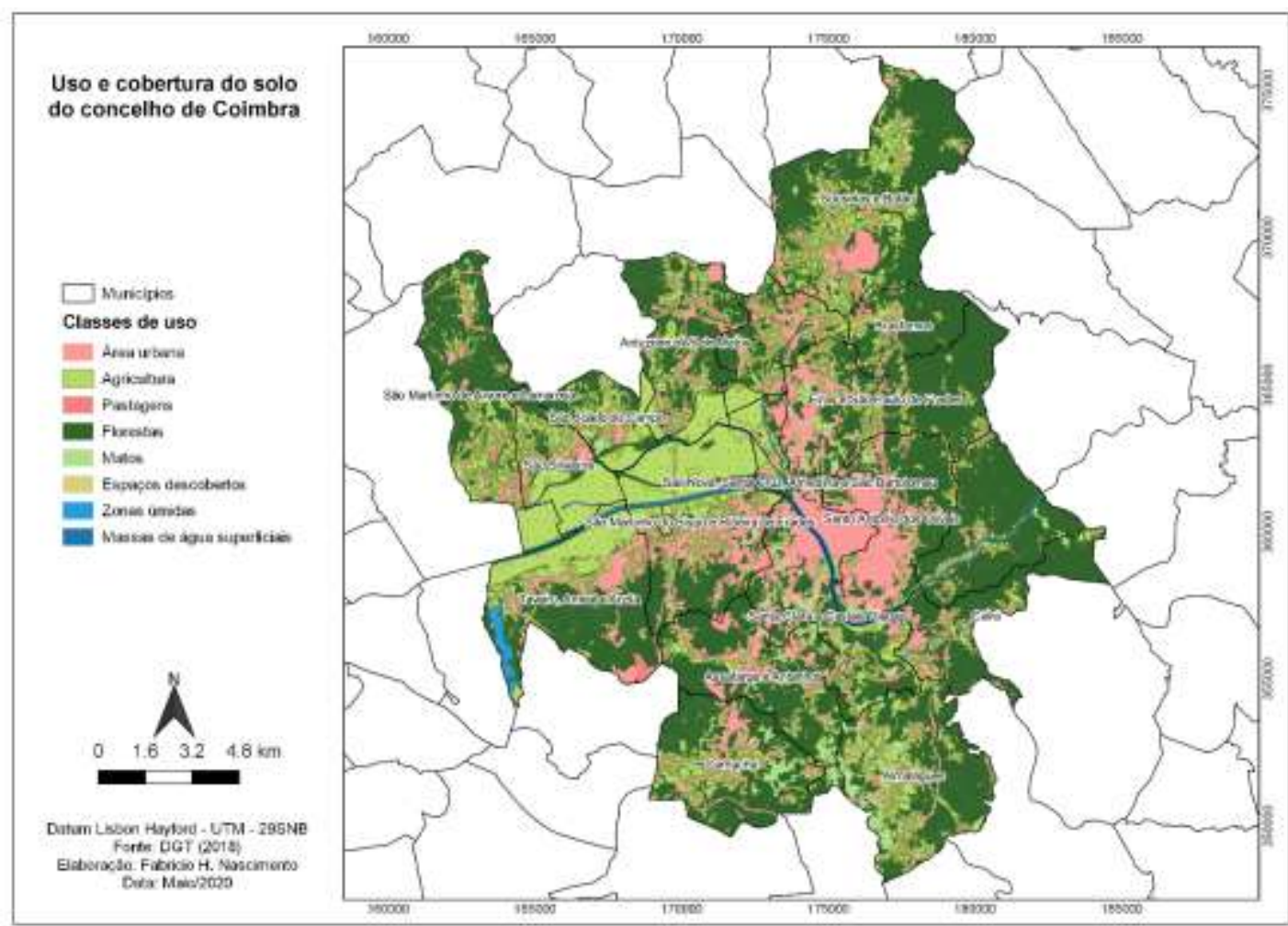

Figura 2 - Uso e cobertura do solo do Concelho de Coimbra Fonte: DGT (2018). Elaborado pelos autores/2020.

Tabela 1 - Estatística de uso do Concelho de Coimbra

\begin{tabular}{lll}
\hline Classes de uso & Área_km² & Percentual \\
\hline Área urbana & $\mathbf{6 . 1 7 5 . 4 5 3}$ & $\mathbf{1 8 , 9 1}$ \\
Agricultura & $\mathbf{9 . 5 6 4 . 1 8 8}$ & $\mathbf{2 9 , 2 8}$ \\
Pastagens & 270.397 & 0,83 \\
Florestas & $\mathbf{1 5 . 5 2 7 . 9 4 9}$ & $\mathbf{4 7 , 5 4}$ \\
Matos & 784.233 & 2,40 \\
Solo exposto & 0.06283 & - \\
Zonas úmidas & 0.88865 & - \\
Massas de água superficiais & 338.464 & 1,04 \\
\hline Total & $\mathbf{3 2 . 6 6 0 . 6 8 4}$ & $\mathbf{1 0 0}$ \\
\hline
\end{tabular}

Elaborado pelos autores/2020.

\subsection{METODOLOGIA}

Para que os resultados desse trabalho fossem obtidos, foi necessário dividi-lo em pelo menos três fases (Figura 3 ). 


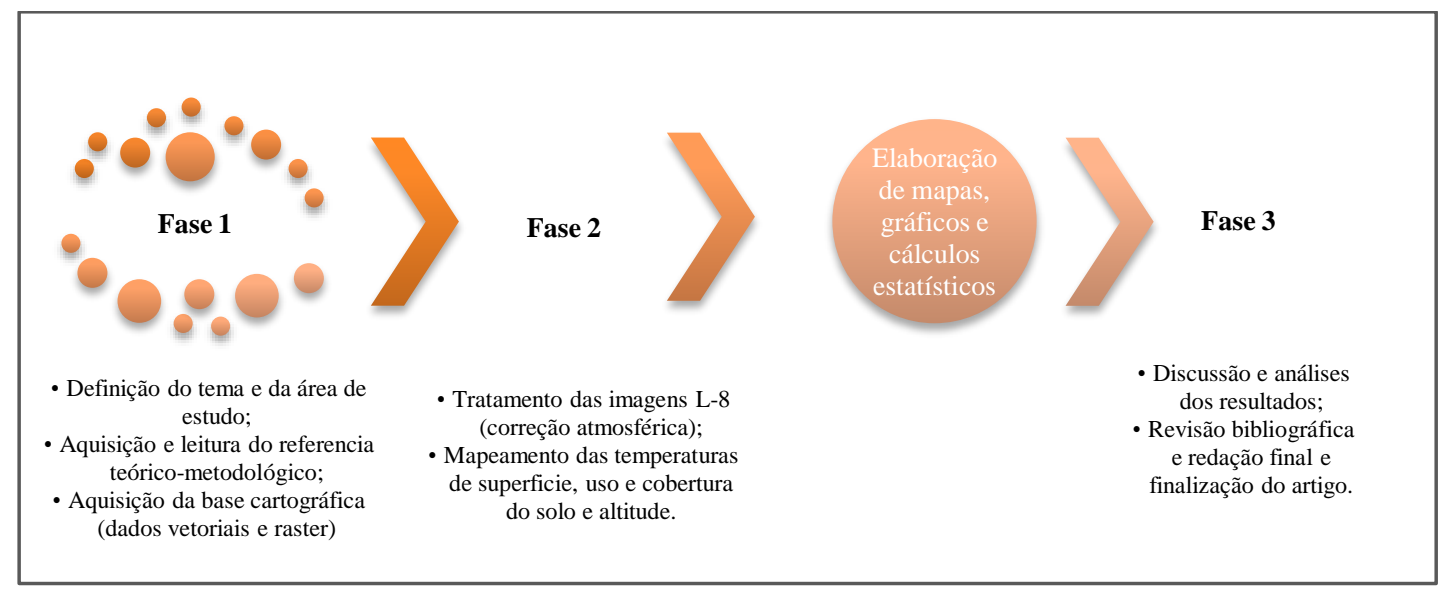

Figura 3 - Fluxograma simples das fases de execução do trabalho. Elaborado pelos autores/2020.

A primeira fase refere-se ao levantamento e leitura do referencial teórico-metodológico acerca dos principais conceitos abordados, como Clima, análise geográfica do clima, Sistema de Informações Geográficas (SIG), Sensoriamento Remoto (SR) e aplicações de SR em estudos Geográficos, em especial da análise das temperaturas de superfície, entre livros, teses, dissertações e artigos científicos, que foram fundamentais na construção do embasamento teórico-metodológico. Ainda nessa fase, foram adquiridas as imagens de satélite utilizadas para o mapeamento das temperaturas de superfície, da United States Geological Survey (USGS), por meio do site do Earth Explorer e outras bases cartográficas, em formato shapefile, para a composição de outros mapas, a exemplo do uso e cobertura do solo de Coimbra, através do site da Direção Geral do Território (DGT).

O satélite escolhido foi o Landsat-8, com 11 bandas e dois sensores, 0 OLI (bandas 1 a 9) e o TIRS (bandas 10 e 11). As bandas do sensor OLI, possuem 30 metros de resolução espacial, exceto a banda 8 (pancromática) com 15 metros. Inicialmente, as bandas 10 e 11 possuíam 100 metros de resolução espacial, mas, foram tratadas e disponibilizadas pela USGS com 30 metros. A resolução temporal é de 16 dias, fator importante, pois possibilita estudos multitemporais de diversos fenômenos da superfície da Terra.

O critério de seleção das imagens levou em consideração, pelo menos, três fatores: o primeiro é que todas as imagens são disponibilizadas de forma gratuita; o segundo é a cobertura de nuvens, com menos de $20 \%$; e terceiro referente as datas de passagem semelhantes e representativas das estações de verão e inverno para o Concelho de Coimbra.

A segunda fase foi dedicada ao mapeamento das temperaturas de superfície no município de Coimbra, em dois períodos, no verão e inverno, em $05 / 08 / 2018$ às $11 \mathrm{~h}$ e $13 \mathrm{~min}$ e $10 / 02 / 2018$ às $11 \mathrm{~h}$ e $14 \mathrm{~min}$, respectivamente. Para tanto, foi feito o recorte espacial das imagens com base na área de estudo. Adicionalmente, foram ainda elaborados outros mapas, como o de uso e cobertura do solo e o MDE para auxiliar na interpretação dos mapas de temperatura, pois estes são dois fatores que influenciam de forma significativa a temperatura à escala local (MENDONÇA; DANNI-OLIVEIRA, 2007; AYOADE, 2013). 
Para a realização do mapeamento, foi necessário abrir um projeto em um software de Sistema de Informações Geográfica (SIG). O projeto foi configurado no sistema de coordenadas Universal Transversa de Mercator (UTM) e sistema de referência Datum Lisbon Hayford. Essa padronização cartográfica é importante, pois garante ao mapeamento integridade e confiabilidade (FITZ, 2008).

Após esse procedimento, foi realizada a correção atmosférica. De acordo com Pires; Ferreira Júnior (2015), a correção atmosférica é importante para efeito de estudos de temperatura de superfície, pois as imagens de satélite, que possuem o canal termal, possuem limitações devido aos efeitos de absorção e espalhamento causados pela atmosfera durante a passagem do sensor.

As temperaturas de superfície foram obtidas através da banda termal 10, correspondente à faixa do infravermelho termal, entre 10.6 - $11.19 \mu \mathrm{m}$, e resolução espacial de 30 metros. O software de SIG utilizado foi o QGIS, versão 2.18, através da ferramenta Semi-Automática Classification Plugin.

$\mathrm{Na}$ ferramenta mencionada foram executados dois comandos necessários à obtenção das temperaturas: correção atmosférica e extração da temperatura de brilho em graus Celcius. A Metodologia aqui empregada foi uma adaptação de Chander et al. (2009) que considera os elementos de conversão para radiância e a constante de calibração da banda termal, conforme Equação 1, que são traduzidos no $L \lambda=(($ Imax $\lambda-\lambda$ Lmin) /(QCALMAX-QCALMIN)) *(QCALQCALMIN) $+\lambda$ Lmin

Quadro 1 e melhor explicadas adiante.

$\mathrm{L} \lambda=((\operatorname{Imax} \lambda-\lambda \mathrm{Lmin}) /(\mathrm{QCALMAX}-\mathrm{QCALMIN})) *(\mathrm{QCAL}-\mathrm{QCALMIN})+\lambda \mathrm{Lmin}$

Quadro 1 - Elementos e valores da fórmula de conversão da radiância

\begin{tabular}{|l|l|}
\hline $\mathrm{L} \lambda$ & Radiância Espectral em sensor de abertura em Watts. \\
\hline QCAL & Valor quantizado calibrado pelo pixel em DN. \\
\hline Lmin $\lambda$ & $\begin{array}{l}\text { Radiância espectral, que é dimensionado para QCALMIN } \\
\text { em Watts }=0.000 .\end{array}$ \\
\hline LMax $\lambda$ & $\begin{array}{l}\text { Radiância espectral, que é dimensionado para QCALMAX } \\
=17.040 .\end{array}$ \\
\hline QCALMIN & $\begin{array}{l}\mathrm{O} \text { mínimo valor quantizado calibrado pixel } \\
\text { (correspondente a Lmin } \lambda \text { ), em DN }=1 .\end{array}$ \\
\hline QCALMAX & $\begin{array}{l}\text { Máximo valor quantizado calibrado pixel (correspondente } \\
\text { a LMax } \lambda \text { ) no DN }=255 .\end{array}$ \\
\hline
\end{tabular}

Fonte: Adaptado de Chander et al. (2009).

Para a obtenção das temperaturas em graus Celsius $\left({ }^{\circ} \mathrm{C}\right)$, foi aplicada a fórmula da Equação 2 e depois subtraídas por 273,15, pois inicialmente as temperaturas são obtidas em Kelvin.

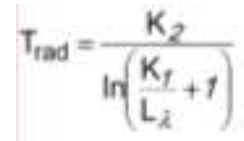

Em que: 
$\mathrm{T}=$ Temperatura efetiva no satélite em Kelvin;

$\mathrm{K} 2$ = Constante de calibração $=1321.0789$;

$\mathrm{K} 1$ = Constante de calibração $=774.8853$;

$L_{\lambda}=$ Radiância espectral em Watts / (metro quadrado).

A Equação 1 é referente a fórmula usada para a conversão dos níveis digitais da imagem para radiância e a Equação 2 trata da conversão dos dados da banda 10 do Landsat - 8 para temperatura de superfície. Assim, é importante ressaltar a relação dos elementos constituintes das fórmulas apresentadas. De acordo com Santos (2014), os sensores disponíveis nos satélites medem a intensidade do fluxo radiante da superfície imageada, o que se denomina de radiância ou radiância aparente, pois sua composição possui interferência da atmosfera e de elementos vizinhos, efeito corrigido a partir da correção atmosférica (Equação 3), conforme proposta de Barsi (2003). Ademais, essa radiância é convertida em números digitais escalonados que são as constantes de calibração de cada banda. Nesse caso, da banda 10 e banda 11, do L-8. Assim, como em alguns estudos que objetivam identificar a refletância aparente da superfície, os números digitais devem ser convertidos em fatores de refletância da superfície.

$$
L_{T}=\frac{L_{T O A}-L_{u}-(1-\varepsilon) L_{d}}{\tau \varepsilon}
$$

Em que:

$\mathrm{LT}=$ Radiância de um alvo negro de temperatura cinética $(\mathrm{W} / \mathrm{m} 2 \cdot \mathrm{sr} \cdot \mu \mathrm{m})$;

LTOA = Radiância espectral $\left(\mathrm{W} / \mathrm{m}^{2} \cdot \mathrm{sr} \cdot \mu \mathrm{m}\right)$;

$\mathrm{T}=$ Transmissividade da atmosfera;

$\varepsilon=$ Emissividade da superfície;

$\mathrm{Lu}=$ Radiância emitida pela superfície $\left(\mathrm{W} / \mathrm{m}^{2} \cdot \mathrm{sr} \cdot \mu \mathrm{m}\right)$;

$\mathrm{Ld}=$ Radiância recebida pela superfície $\left(\mathrm{W} / \mathrm{m}^{2} \cdot \mathrm{sr} \cdot \mu \mathrm{m}\right)$.

A terceira etapa foi dedicada as análises, discussão dos resultados e redação final do artigo. Essa metodologia foi testada por diversos autores, nos âmbitos internacional e nacional, a exemplo de Chander et al. (2009), Jensen (2009), Correa et al. (2015), Porangaba; Amorin (2019). Nestes dois últimos casos foram identificadas áreas com forte emitância termal relacionadas as áreas construídas, pavimentadas e outras superfícies características de áreas urbanas. Tal fato indica relação existente entre as elevadas temperaturas de superfície e os materiais construtivos que, em sua maioria, são caracterizados por baixa capacidade de dissipação do calor.

\section{RESULTADOS E DISCUSSÕES}

\subsection{TEMPERATURA DE SUPERFÍCIE NO VERÃO}

A temperatura de superfície, assim como a temperatura do ar, pode ser definida como uma variável da climatologia e reflete a relação entre a superfície e a atmosfera. Todavia, é importante ressaltar que a temperatura de superfície 
reflete o fluxo de calor que é emitido e/ou refletido por um objeto, ou seja, dos materiais que compõem a paisagem e exerce influência significativa na temperatura do ar, definida como o calor sensível armazenado no ar nas camadas mais baixas do clima urbano (VOOGT; OKE, 2003; MENDONÇA; DANNI-OLIVEIRA, 2007).

Segundo o Instituto Português do Mar e da Atmosfera (IPMA, 2018) no dia 05/08/2018, mesmo dia da passagem do satélite, a temperatura média foi de $21^{\circ} \mathrm{C}$, e a máxima registrada foi de $38,2^{\circ} \mathrm{C}$. Entre os dias 4 e 5 de agosto não houve precipitação e com o céu sem cobertura de nuvens. Nesse contexto, o mês de agosto de 2018 foi o segundo mês mais quente depois de 2003 e foi classificado como extremamente quente para Portugal Continental. Nesse contexto, os dias mais quentes foram observadas no período de 1 a 6 de agosto, com valores de temperatura do ar acima dos $32^{\circ} \mathrm{C}$. Nesse âmbito, entre os dias 3 e 5, as áreas relacionadas a Portugal Continental foram influenciadas por um Anticiclone a Oeste e Sudoeste dos Açores, bem como por uma Depressão a Norte de Marrocos. Além disso, o dia 5 de agosto, mesmo dia da passagem do satélite, foi considerado o dia mais quente do século XXI, até o momento (IPMA, 2018).

Essas informações são importantes, na medida que, em dias de céu claro, a incidência da radiação solar sobre a superfície é mais intensa, favorecendo o aumento das temperaturas de superfície (COELHO, 2013).

A Figura 4 apresenta as classes de temperatura de superfície do município de Coimbra, em 5 de agosto de 2018 às $11 \mathrm{~h}$ e $13 \mathrm{~min}$ da manhã, horário local de Lisboa. De acordo com o mapa, a temperatura máxima registrada para o dia/hora avaliado foi de $35,5^{\circ} \mathrm{C}$, e mínima de $27,5^{\circ} \mathrm{C}$. As áreas que apresentaram as temperaturas mais elevadas para o dia/hora em questão foram as porções Norte, Nordeste, Central, Sul e um trecho da porção Sudoeste. Essas altas temperaturas podem estar associadas ao tipo de uso e cobertura do solo que, em sua maioria, é caracterizada por áreas desflorestadas, asfalto, concretos e usos industriais ou comerciais, a exemplo da fábrica de Cimentos de Portugal (CIMPOR) localizada em Souselas, Nordeste de Coimbra e outros materiais não-evaporativos e não-porosos, como o asfalto, por exemplo. Nesse sentido, Jensen (2009) afirma que esse tipo de material introduz uma significativa quantidade de energia calórica na paisagem urbana e consequentemente reduz a evapotranspiração e aumenta as temperaturas da paisagem.

Vale ressaltar que, nas porções Central e um trecho das Porções Norte (São Silvestre) e Leste (São Martinho do Bispo) caracterizaram-se por temperaturas mais baixas, entre 27,5 e $29,5^{\circ} \mathrm{C}$, possivelmente associadas pela presença do corpo d'água, o Rio Mondego e áreas com a presença de vegetação, uso agrícolas e áreas úmidas, exercendo papel fundamental na liberação de umidade e, consequentemente, na elevação do calor específico do ambiente.

A partir da análise da Figura 5 é possível visualizar a dimensão do Rio Mondego, pelo menos do trecho que corta a região Central do Concelho de Coimbra, à esquerda. À direita, uma vista de um ponto mais alto do Concelho, notadamente da Universidade de Coimbra que permite identificar o centro de Coimbra densamente urbanizado, embora haja ocorrência de áreas verdes no local que podem atuar como fator de variação das temperaturas, não necessariamente na atenuação das mesmas (JARDIM, 2010). 


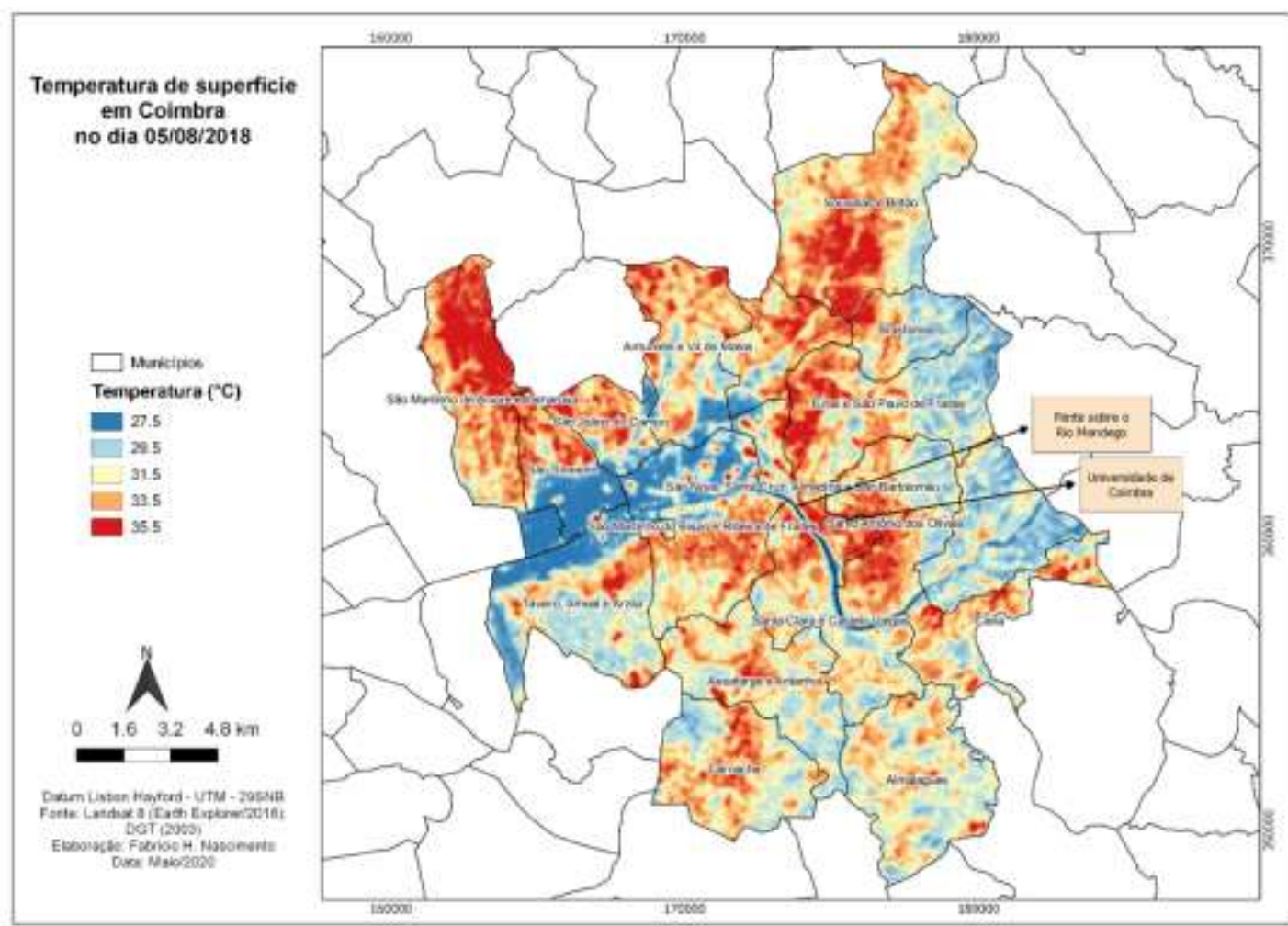

Figura 4 - Temperatura de superfície no período de verão em Coimbra. Fonte: DGT (2003); USGS (2018). Elaborado pelos autores/2020.
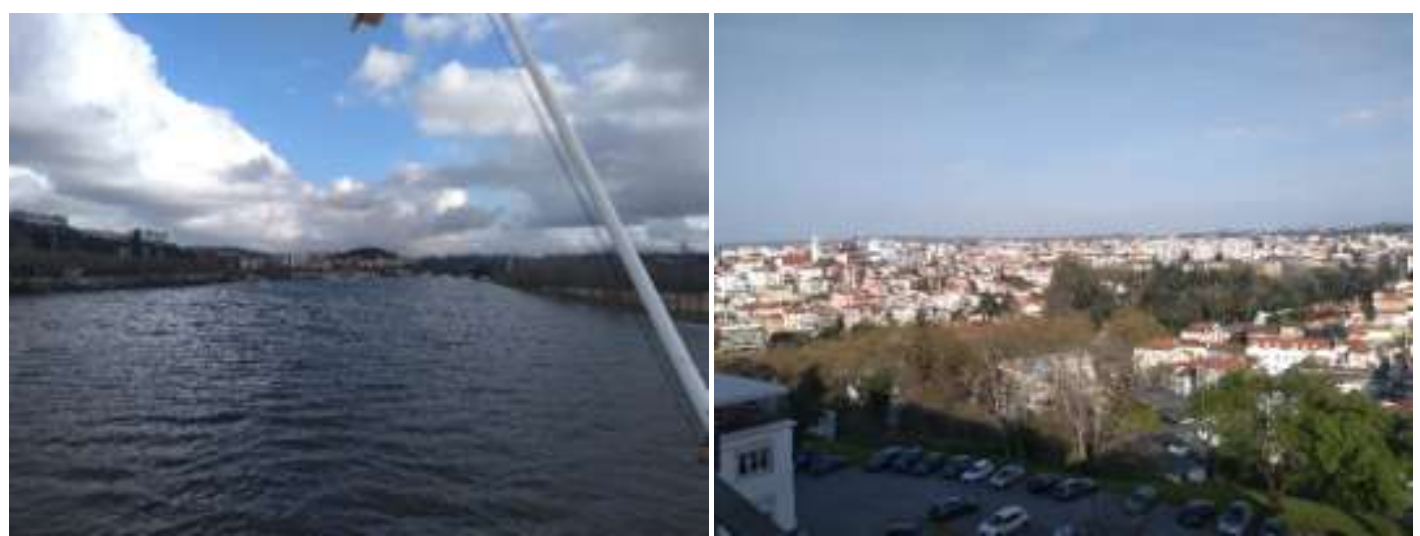

Figura 5 - Fotos de um trecho do Rio Mondego, em Coimbra (à esquerda) e vista da porção central de Coimbra (à direita). Fotos dos autores/2020.

\subsection{TEMPERATURA DE SUPERFÍCIE E USO E COBERTURA DO SOLO NO VERÃO}

A Figura 6 é uma aproximação da porção Central do Concelho de Coimbra e apresenta a relação entre o uso e cobertura do solo e as classes de temperatura de superfície para o período do verão, além de um perfil campotérmico A-B (Figura 7). As classes de uso e cobertura do solo que apresentaram temperaturas elevadas foram área urbana, agricultura, pastagens e solo exposto, com valores entre 31,5 a $35,5^{\circ} \mathrm{C}$, em especial a porção Central de 
Coimbra, a zona mais urbanizada onde as temperaturas chegam aos $35,5^{\circ} \mathrm{C}$. Por outro lado, a norte do mapa, há uma concentração de temperaturas mais baixas, entre 27 e $29^{\circ} \mathrm{C}$, embora seja caracterizada por zonas agrícolas, pastagens e zonas úmidas. Resultados Semelhantes foram encontrados por Quattrochi; Ridd (1994) e Lo et al. (1997) nas cidades de Salt Lake City, Utah, e Huntsville, no Alabama, onde as menores temperaturas no período diurno, foram encontradas nos corpos d'água, áreas de vegetação e terras agrícolas.

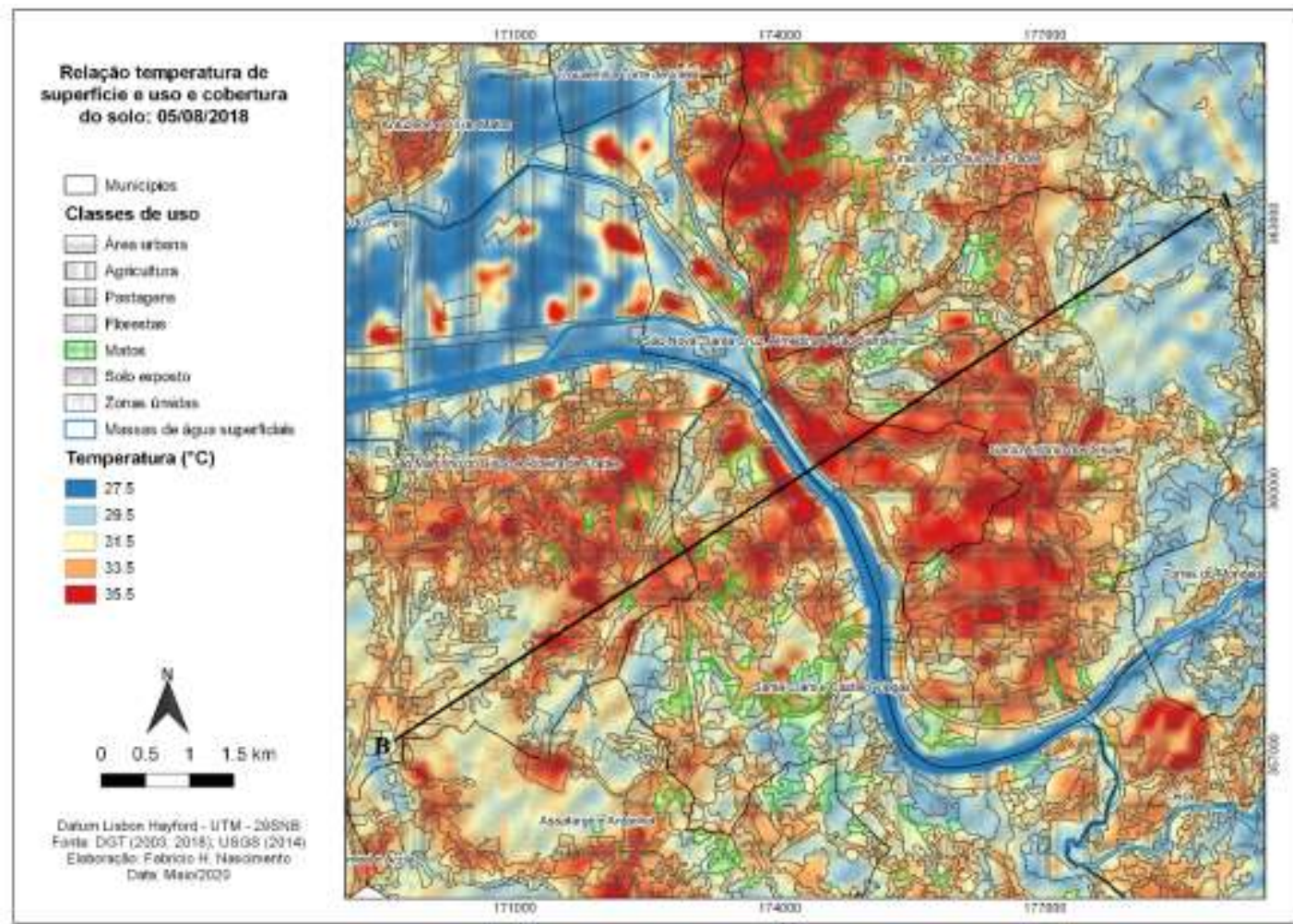

Figura 6 - Relação Temperatura de superfície e uso e cobertura do solo no verão. Fonte: DGT (2018); USGS (2014). Elaborado pelos autores/2020.

Na porção Leste, caracterizada por zonas de florestas, concentram-se as temperaturas mais baixas. Nesse contexto, é possível inferir que a vegetação ali encontrada exerce um papel essencial na atenuação da temperatura. Sobre esse assunto, Ganho (1996), afirma que "[...] como consequência de um balanço térmico de características particulares, os espaços verdes arbóreos apresentam normalmente temperaturas mais baixas do que o espaço urbanizado em que se inserem [...]" (p.36), embora há ocasiões que isso pode não ocorrer, caso que também foi verificado neste trabalho.

O perfil campo-térmico A-B evidencia o comportamento da temperatura em função dos diferentes usos e cobertura do solo ao longo de 1.200 metros, conforme a Figura 7. Neste âmbito, as áreas de florestas apresentaram temperaturas mais baixas, abaixo dos $30^{\circ} \mathrm{C}$, enquanto as áreas descobertas, áreas com cultivos agrícolas e artificializadas registraram temperaturas entre 31,5 a $35,5^{\circ} \mathrm{C}$. Também é possível identificar que, no trecho do perfil associado ao Rio Mondego, há uma queda substancial da temperatura, abaixo dos $28^{\circ} \mathrm{C}$. 


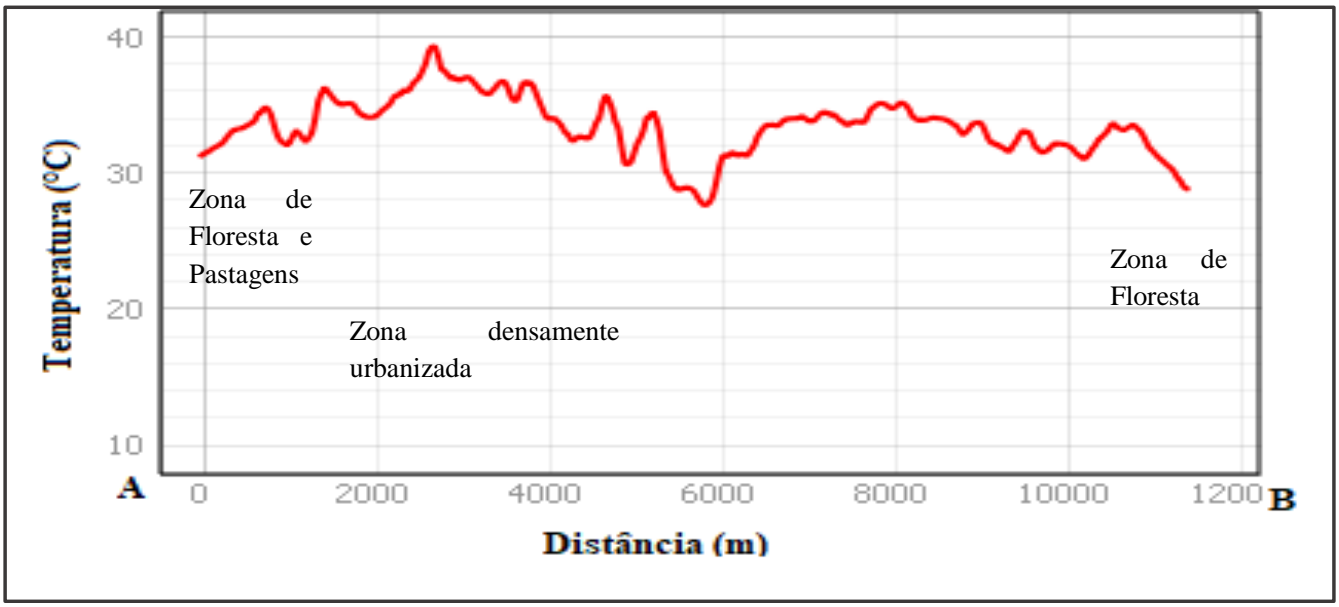

Figura 7 - Perfil campo-térmico A-B para o verão. Elaborado pelos autores/2020.

Correa et al. (2015), afirmam que alguns usos do solo, em especial os artificializados, possuem baixo calor específico e pouca eficiência em dissipar calor, fato que corrobora para que as temperaturas de superfície sejam mais elevadas em ambientes artificializados. Outro fator que também pode corroborar para que altas temperaturas de superfície possam se concentrar em áreas urbanizadas, é o albedo dos materiais, aqui entendido como a capacidade de um objeto de refletir a insolação. Assim, materiais como asfalto, concretos, telhados escuros, tendem a armazenar mais calor ao longo do dia, enquanto que áreas verdes, como florestas, gramas e corpos d'água naturais tendem a armazenar menos calor (CHRISTOPHERSON, 2013).

No entanto, é possível observar também que na porção central há concentração de temperaturas mais elevadas, embora a área mencionada seja caracterizada por vegetação e parques verdes: Choupalinho à beira-rio, na margem esquerda; parque Manuel Braga e Jardim Botânico na margem direita. Neste sentido, Jardim (2010) afirma que nem sempre a vegetação exerce um papel atenuador da temperatura, mas sim de variação. Se as áreas verdes ocorrerem de forma pontual ou esparsada, é possível que as temperaturas nesse ambiente possam ser mais elevadas, caso verificado na situação mencionada.

\subsection{TEMPERATURA DE SUPERFÍCIE NO INVERNO}

A Figura 8 refere-se às temperaturas de superfície do Concelho de Coimbra no período de inverno, em 10/02/2018 às $11 \mathrm{~h}$ e14 min da manhã, hora local de Lisboa. Nesse contexto, as temperaturas foram distribuídas em cinco classes, sendo que a maior temperatura registrada para o dia/hora da passagem do satélite foi de $13^{\circ} \mathrm{C}$ e a menor foi de $6^{\circ} \mathrm{C}$, com temperatura média de $9,5^{\circ} \mathrm{C}$.

Segundo o IPMA, nos dias 9 e 10 de fevereiro de 2018, ocorreu 3,05mm e $0 \mathrm{~mm}$ de precipitação, respectivamente, com céu claro a parcialmente nublado, condições que estão diretamente ligadas às características das temperaturas de superfície da área de estudo. As temperaturas médias do ar registradas para esses dias foram de $4,5^{\circ} \mathrm{C}$ e $3,2^{\circ} \mathrm{C}$, respectivamente. 


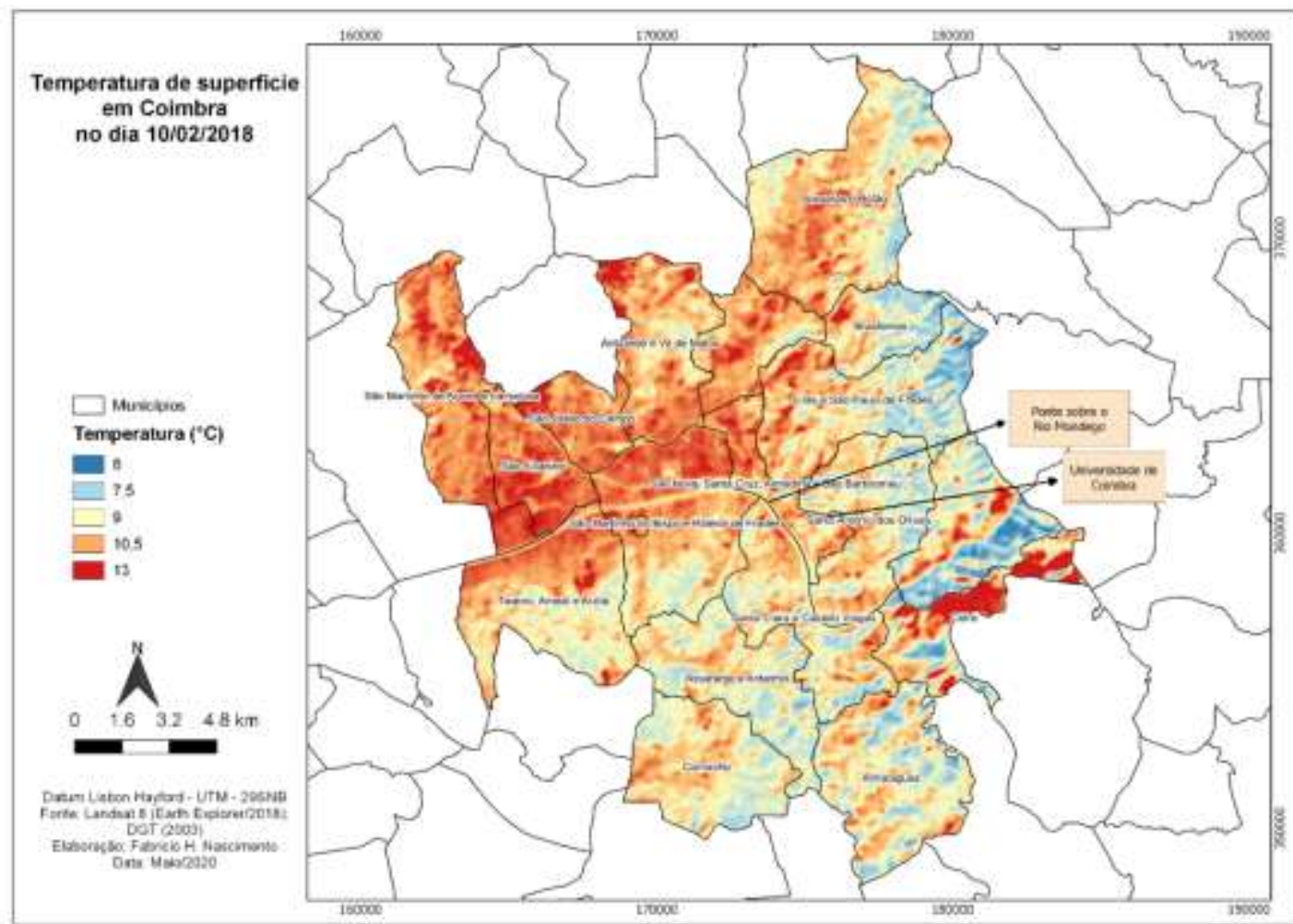

Figura 8 - Temperatura de superfície no período de inverno em Coimbra Fonte: DGT (2003); USGS (2018). Elaborado pelos autores/2020.

Pela análise da Figura 8 é observado que as temperaturas mais elevadas se encontram nas porções Norte, Central e uma pequena área na porção Sudeste de Coimbra, locais com altitudes relativamente baixas, exceto a porção Sudeste, com altitudes que variam de 162 e 316 metros.

Os valores elevados de temperatura podem ser justificados pelo tipo de uso e cobertura do solo, pois as porções Norte e Central são predominantemente caracterizadas por áreas agrícolas e territórios artificializados, enquanto a porção Sudeste tem maior parte de sua superfície coberta por florestas. Esses resultados estão de acordo com as teorias de que a redução de áreas verdes e de corpos hídricos em detrimento da construção de áreas edificadas, corrobora com o aumento das temperaturas nos ambientes urbanizados (GARCÍA, 1990).

Estruturas de concreto, asfalto e até mesmo espaços descobertos, a exemplo de solo exposto, afloramentos rochosos, possuem baixo calor específico e pouca eficiência no que se refere à dissipação da energia recebida do Sol, o que pode causar superaquecimento em boa parte do dia (CORREA et al., 2015). Todavia, conforme aponta Jardim (2010), nem sempre as áreas mais urbanizadas serão mais quentes e as áreas com vegetação mais frias. Além dos contrastes térmicos em áreas urbanas serem elevados, pois os materiais construtivos necessitam de pouca energia para se aquecerem (decorrente dos baixos valores de calor específico), também perdem calor mais rapidamente. Nas áreas cobertas por vegetação e proximidades à corpos hídricos, os ambientes demoram mais tempo para se aquecerem e para se resfriarem, resultado da presença de umidade no ambiente, que eleva as características de 
calor específico e capacidade térmica do ambiente, combinado à reduzida propagação de calor pelo tecido vegetal.

\subsection{TEMPERATURA DE SUPERFÍCIE E USO E COBERTURA DO SOLO NO INVERNO}

A figura 9 é uma aproximação da porção central do Concelho de Coimbra demonstrando a relação entre as classes de temperatura com o uso e cobertura do solo no período de inverno, e melhor detalhado pelo perfil campo-térmico AB (Figura 10).

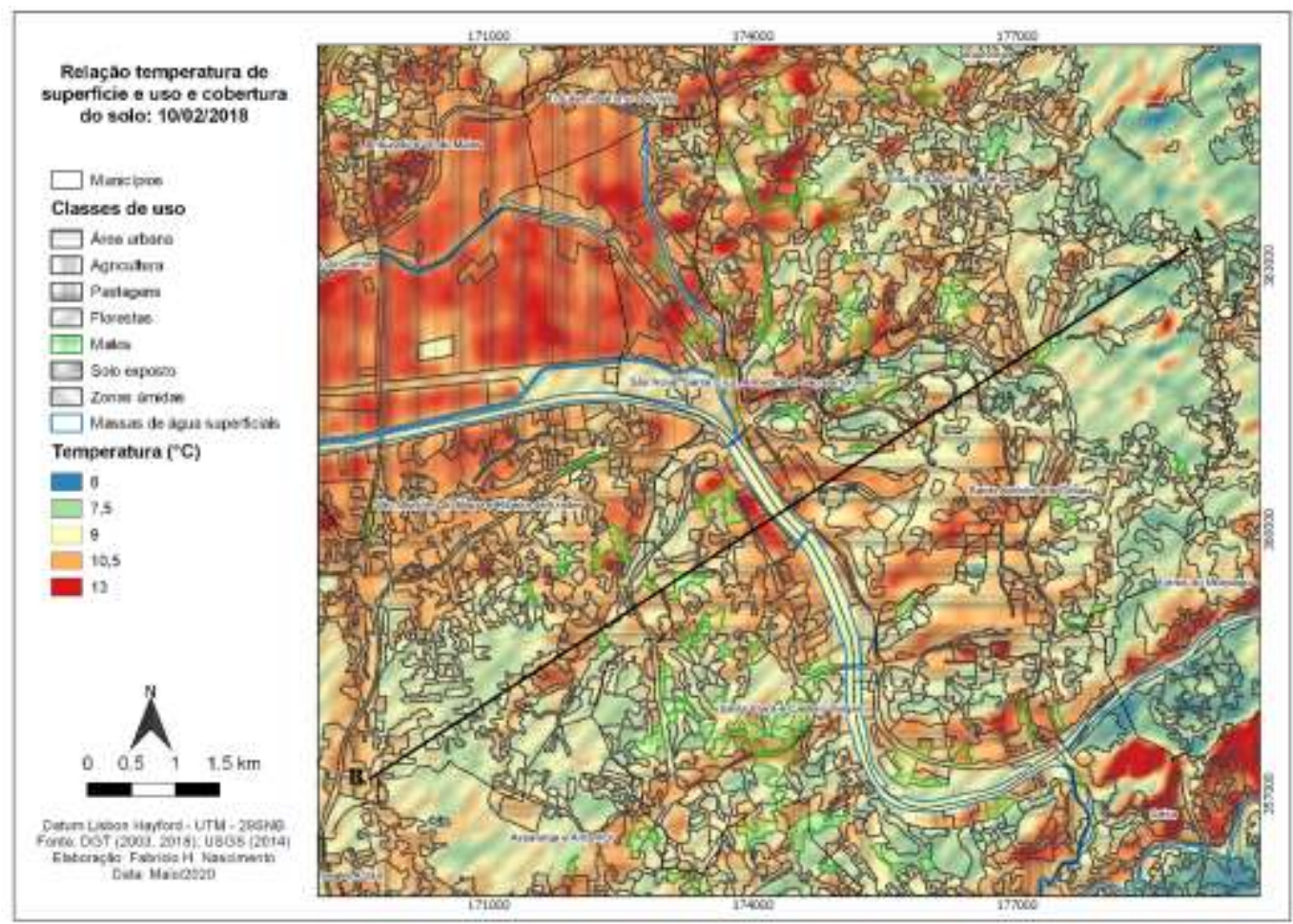

Figura 9 - Relação temperatura de superfície e uso e cobertura do solo no inverno. Fonte: DGT (2018); USGS (2014). Elaborado pelos autores/2020.

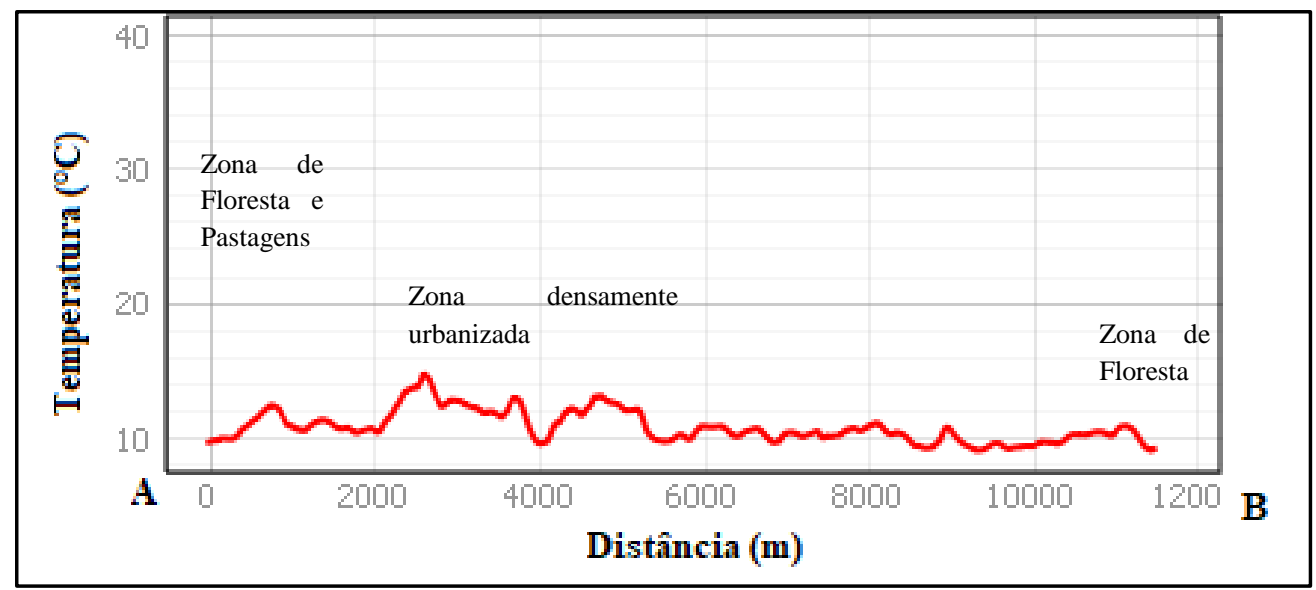

Figura 10 - Perfil campo-térmico A-B no inverno. Elaborado pelos autores/2020. 


\subsection{FREQUÊNCIA DOS INTERVALOS DE TEMPERATURA}

A Figura 11 é um histograma que tem o objetivo de apresentar a distribuição de pixels que podem ser verificados em uma imagem, ou seja, a quantidade de pixels por nível de cinza (FITZ, 2008). Nesse contexto, a distribuição dos pixels, geralmente está vinculada a um valor, que neste caso refere-se ao valor da temperatura.

Por meio da análise da figura, é possível perceber que no verão a concentração de pixels ocorre no intervalo entre nos valores de 29 a 35 e no inverno entre 8 a 13. Nesse contexto, nota-se que as temperaturas mais elevadas ocorreram num intervalo de tempo maior, em detrimento das temperaturas mais baixas, nos dois casos investigados.

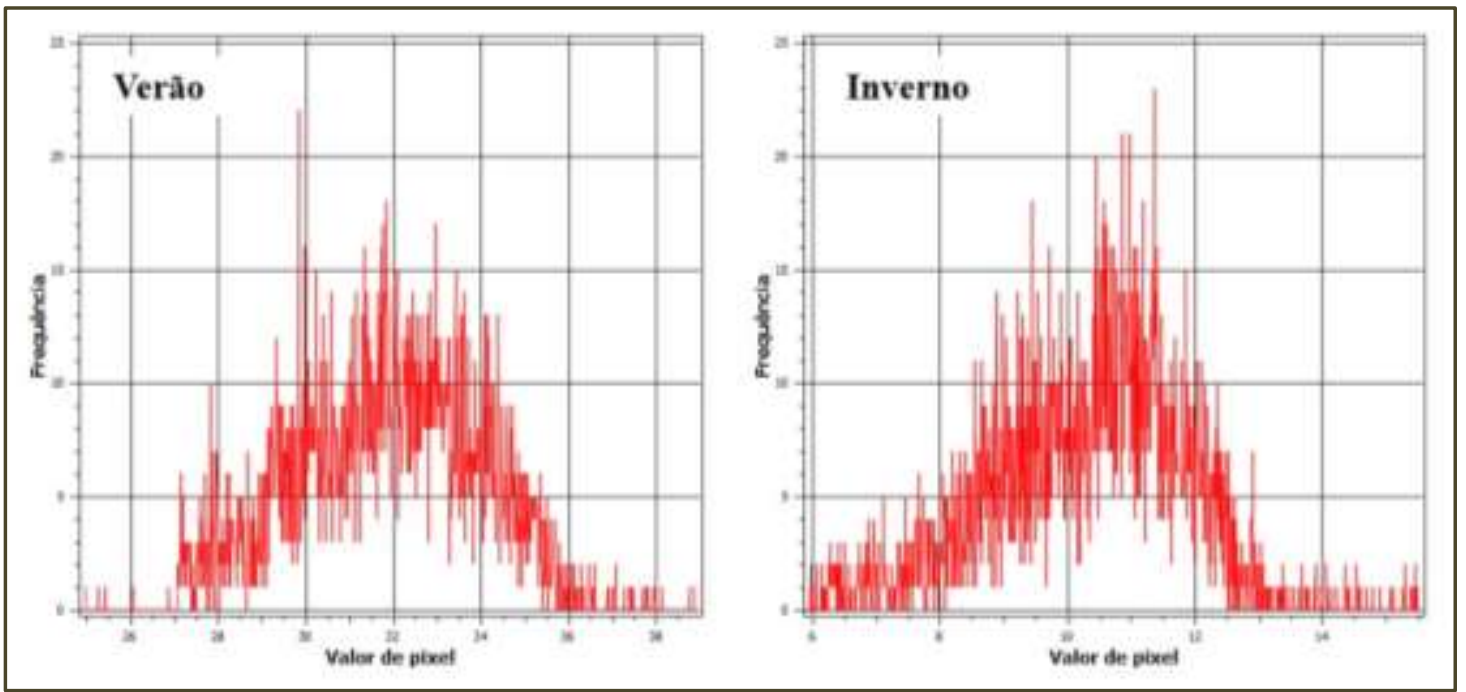

Figura 11 - Distribuição dos pixels das imagens do satélite Landsat-8 nos períodos de verão e inverno. Elaborado pelos autores/2020.

\section{CONSIDERAÇÕES FINAIS}

A metodologia aqui empregada se mostrou eficaz, em certa medida, e permitiu uma série de considerações acerca da relação entre as temperaturas de superfície e o uso e ocupação do solo no Concelho de Coimbra, considerando as especificidades do dia/hora das imagens utilizadas. Dessa forma, os resultados encontrados dialogam com as principais teorias acerca dos efeitos que as ações humanas trazem ao ambiente, em especial à variação dos elementos atmosféricos.

Os resultados extraídos durante a passagem do satélite evidenciaram zonas em Coimbra com faixas de temperatura elevadas, a exemplo dos territórios modificados pela ação humana e outras paisagens peculiares de áreas urbanas que, tanto no verão quanto no inverno, apresentaram as temperaturas mais elevadas. Além disso, as áreas de pastagens e agricultura também apresentaram tendência termal elevada, pois a vegetação de baixo porte oferece pouca resistência à movimentação do ar (não impede a advecção de calor entre as diferentes localidades) e menor recobrimento foliar, permitindo que a radiação solar atinja o solo com maior facilidade. 
Não é pretensão desse estudo esgotar aqui as possibilidades de análise, mas abrir caminhos para que outras propostas envolvendo o uso de técnicas em SR possam continuar/aperfeiçoar esta pesquisa. É importante ressaltar que as imagens de satélites são geradas em uma escala temporal relativamente curta, a exemplo do Landsat-8 com recorrência temporal de 16 dias, permite que estudos como este possam ser desenvolvidos de maneira contínua, proporcionando aos gestores e à sociedade maior aporte de informações consistentes sobre clima urbano.

Além disso, a utilização de imagens de satélites não permite apenas o conhecimento dos diferentes comportamentos dos materiais constituintes da superfície analisada em relação à radiação solar, mas, também, compreender a evolução espaço-temporal de áreas urbanas e outros territórios modificados pela ação humana.

Cabe destacar, também, o uso de dados e ferramentas de acesso livre (imagens de satélite, dados vetoriais e raster e produtos cartográficos elaborados em ambiente de SIG), o que permite acesso e utilização mais facilitados, muito embora haja limitações ao se apropriar dessas ferramentas, exigindo conhecimento e cuidados por parte dos usuários envolvidos, além de articulação com outros procedimentos metodológicos, como verificações in loco por meio de trabalho de campo, a exemplo da coleta de dados de temperatura por meio de instrumentos registradores. O uso indiscriminado da tecnologia, sem os devidos cuidados, pode gerar resultados contraproducentes (FITZ, 2008).

\section{REFERÊNCIAS BIBLIOGRÁFICAS}

AYOADE, J. O. Introdução à climatologia para os trópicos. $17^{\circ}$. ed. São Paulo: Bertrand Brasil, 2013, 350 p.

BARSI, J.A.; Barker, J.R. S. An Atmospheric Correction Parameter Calculator for a Single Thermal Band Earth-Sensing Instrument. IGARSS03, 21-25 July 2003, Centre de Congres Pierre Baudis, Toulouse, France.

BASE DE DADOS PORTUGAL CONTEMPORÂNEO - PORDATA. Informações por municípios: Coimbra. Disponível em <https://www.pordata.pt/Municipios>, acesso em 05 maio 2020.

CHANDER, G.; MARKHAM, B. L.; HELDER, D. L. Summary of current radiometric calibration coefficients for Landsat MSS, TM, ETM+, and EO-1 ALI sensors. Remote Sensing of Environment, 2009, 113, p. 893-903.

CLIMATE-DATA.ORG. Clima Coimbra. Disponível em <https://pt.climatedata.org/europa/portugal/coimbra/coimbra-160/>, acesso em 12 maio 2020.

COELHO, A.L.N. Distribuição das Classes de Temperatura de Superfície a Partir da Faixa do Infravermelho Termal do Sensor TM/Landsat-5 no Município de Vitória (ES). Anais XVI Simpósio Brasileiro de Sensoriamento Remoto - SBSR, Foz do Iguaçu, PR, Brasil, 13 a 18 de abril de 2013, INPE.

COLLISCHONN, E. A temperatura de superfície e sua relação com a urbanização no Vale do Rio Pardo-RS. In: XI Encontro Nacional da Associação Nacional de Pós-Graduação e Pesquisa em Planejamento Urbano e Regional, 2005, Bahia. Anais. Bahia: ANPUR. 
CORREA, W.S.C.; COELHO, A.L.N.; VALE, C.C. Influência de distintos sistemas atmosféricos na temperatura de superfície do município de Vitória (ES). Revista Caminhos de Geografia, Uberlândia v. 16, n. 53 Mar/2015 p. 37-54.

CHRISTOPERSON, R. Geossistemas: Uma Introdução à Geografia Física. 7a edição, Porto Alegre, RS, Brasil: Bookman, 2013.

DIREÇÃO GERAL DO TERRITÓRIO - DGT. Base cartográfica de Portugal (limite administrativo, uso e cobertura do solo e arruamentos). Disponível em <http://www.dgterritorio.pt/dados_abertos/>, acesso em 09 maio 2020.

FERREIRA, D. de B. O ambiente climático. Geografia de Portugal, vol. 1 Ambiente Físico. Lisboa: Círculo de Leitores, 2005.

FITZ, Paulo R. Geografia Tecnológica. In: Geoprocessamento sem complicação, São Paulo: Ed. Oficina de Textos, 2008: p. 19-29.

GARCIA, M. C. M. Estudio del clima urbano de Barcelona: la "isla de calor". 193 p. Tese (Doutorado em Geografia) - Universidade de Barcelona, Barcelona, 1990.

GANHO, N. Clima urbano e a climatologia urbana: fundamentos e aplicação ao ordenamento urbano. Cadernos de Geografia, n. - 18, Coimbra, F.L. U. C., pp. 97-127, 1999.

INSTITUTO PORTUGUES DO MAR E DA ATMOSFERA - IPMA. Dados climatológicos de Coimbra. Disponível em <https://www.ipma.pt/pt/otempo/prev.localidade.hora/\#Coimbra\&Coimbra>, acesso em 12 maio 2020.

INSTITUTO PORTUGUES DO MAR E DA ATMOSFERA - IPMA. Boletim climatológico mensal (fevereiro e agosto de 2018). Disponível em <http://www.ipma.pt/pt/publicacoes/boletins.jsp?cmbDep=cli\&cmbTema=pcl\&i $\mathrm{dDep}=$ cli\&idTema $=$ pcl\&curAno=-1>, acesso em 26/06/2020.

JARDIM, C.H. Variações da temperatura do ar e o papel das áreas verdes nas pesquisas de climatologia urbana. Revista de Ciências Humanas, Viçosa, v. 10, n. 1, p. 9-25, jan./jun, 2010.

JENSEN, J. R. Sensoriamento Remoto do Ambiente: uma perspectiva em recursos terrestres. São José dos Campos, SP: Editora Parêntese, 2009, 598p.

JESUS, R.J. de. Avaliação do comportamento da temperatura da superfície terrestre do município de Cariacica (ES) em 1985 E 2013. Dissertação (Mestrado em Geografia). Programa de Pós-Graduação em Geografia da Universidade Federal do Espírito Santo, Vitória/ES, 2016.

LANDSBERG, H. E. O Clima das Cidades. Revista do Departamento de Geografia, n. 18, p. 95-111, 2006.

LOMBARDO, M. A. Ilha de Calor nas Metrópoles: o exemplo de São Paulo. São Paulo: Hucitec: $1985,244 p$.

LO, C. P; QUATTROCHI, D. A; LUVALL, J. C. Application of high-resolution thermal infrared remote sensing and GIS to assess the urban heat island effect. International Journal of Remote Sensing, p. 287-304. Doi: 10.1080/014311697219079, 1997. 
LOPES, A. Modificações no clima urbano de Lisboa como consequência do crescimento urbano. Vento, ilha de calor de superfície e balanço energético. PhD, Centro de Estudos Geográficos, Faculdade de Letras. Lisboa, Universidade de Lisboa, 2003, 375p.

MENDONÇA, F., DANNI-OLIVERIA, I. M. Climatologia: noções básicas e climas do Brasil. São Paulo: Editora Oficina de Texto, 2007, 206p.

MILLS, G. Climatologia urbana: história, status e perspectivas. Urban Clima, vol. 10: 479-489, 2014.

MONTEIRO, C.A.F. Teoria e Clima Urbano. São Paulo: IG06-USP (Série Teses e Monografias n.25), 1976.

MONTEIRO, C.A.F. Análise rítmica em climatologia: problemas da atualidade climática em São Paulo e achegas para um programa de trabalho. Climatologia, São Paulo, n. 1, p. 1-21, 1971.

OKE, T. R. Boundary Layer Climates. Londres: Routledge, 2a ed. 1987, 435 p.

PELLEGRINA, G.J; CUNHA, L. Banco de dados para gestão de riscos de movimentos em massa no município de Coimbra e análise da influência dos principais condicionantes atmosféricos. Cadernos de Geografia no 40, Coimbra, FLUC, p. 7-22, 2019.

PORANGABA, G.F.O; AMORIM, M.C.C.T. Geotecnologias Aplicadas à Análise de Ilhas de Calor de Superfície em Cidades do Interior do Estado de São Paulo. Revista Brasileira de Geografia Física v.12, n.06, p. 2041-2050, 2019.

PORTAL DO CLIMA. Normais climatológicas: histórico simulado 1971-2000 Região de Coimbra. Disponível em <https://www.ipma.pt/pt/otempo/prev.localidade.hora/\#Coimbra\&Coimbra>, acesso em 12 maio 2020.

QUATTROCHI, D. A; RIDD, M. K. Measurement and analysis of thermal energy responses from discrete urban surfaces using remote sensing data. International Journal of Remote Sensing, p. 1991-2022. Doi: 10.1080/01431169408954224, 1994.

RAO, P. K. Remote sensing of urban "heat islands" from an environmental satellite. Bulletin of the American Meteorological Society, Boston, v.53, p.647648, 1972.

RIBEIRO, A.G. As Escalas do Clima. Boletim de Geografia Teorética, n.23, p.288-294, 1993.

ROCHA, R. C. C; CORDEIRO, A. M. R; GONÇALVES, G. R. Uso dos sensores remotos do satélite landsat 8 para identificação de "ilhas de calor" e "lago de ar frio" no Município de Oliveira do Hospital para o ano de 2013, 2014. DOI: 10.13140/2.1.4847.0400, 2014. Disponível em <https://www.researchgate.net/publication/265435348>, acesso em 30 junho 2020.

SINGH, C.K; KUMARI, M; KIKON, N; TOMAR, R.K. Spatiotemporal Analysis of Urban Expansion and Its Impact on Surface Temperature and Water Bodies. In. SING, C.k. (org.). Geospatial Applications for Natural Resources Management. Boca Raton: CRC Press, p. 1-9, 2018. 
SORRE, M. Les Fondements de la Géograhie Humaine. Tome Premier: Les fondaments biologiques. Paris: Armand. Colin, 1951.

WENG, Q. Remote sensing and GIS integration: theories, methods, and applications. New York: McGraw-Hill, 2010.

VOOGT, J. A.; OKE, T.R. Thermal remote sensing of urban climates. Remote Sensing Of Environment, v. 81, p.370-384, 2003 